\title{
Functionalized BODIPY Derivatives as Potential Fluorescent Labels ${ }^{\dagger}$
}

\author{
Raquel C. R. Gonçalves, Mariana B. Nogueira, Susana P. G. Costa and M. Manuela M. Raposo * \\ Centre of Chemistry, University of Minho, Campus de Gualtar, 4710-057 Braga, Portugal; \\ raquelrainha96@gmail.com (R.C.R.G.); marianabarrosnogueira@gmail.com (M.B.N.); \\ spc@quimica.uminho.pt (S.P.G.C.) \\ * Correspondence: Correspondence: mfox@quimica.uminho.pt \\ + Presented at the 22nd International Electronic Conference on Synthetic Organic Chemistry, 15 November- \\ 15 December 2018; Available Online: https://sciforum.net/conference/ecsoc-22.
}

Published: 14 November 2018

\begin{abstract}
Difluoro-4-bora-3a,4a-diaza-s-indacene (BODIPY) derivatives 1 and $\mathbf{2}$ were obtained with $16 \%$ and $33 \%$ yield by a two-step reaction: condensation of a pyrrole with the corresponding aldehyde followed by oxidation with 2,3-dichloro-5,6-dicyano-p-benzoquinone (DDQ) in the presence of boron trifluoride diethyl etherate $\left(\mathrm{BF}_{3} \mathrm{OEt} 2\right)$. The two compounds were characterized by the usual spectroscopic techniques and a detailed photophysical study was undertaken. The compounds exhibited intense absorption bands at $502 \mathrm{~nm}$ and $497 \mathrm{~nm}$, respectively. Emission studies of the compounds 1 and $\mathbf{2}$ showed emission bands with maximum wavelength at $518 \mathrm{~nm}$ and $519 \mathrm{~nm}$, respectively.
\end{abstract}

Keywords: synthesis; BODIPY; chemosensors; fluorescence; labelling

\section{Introduction}

Labels can be attached to proteins, for example antibodies, which accumulate in specific organs for imaging in animals and human subjects. However, there is a growing realization that imaging events in cells and whole organisms by fluorescence is limited by the accessible probes. 4,4-difluoro4-bora-3a,4a-diaza-s-indacene (BODIPY) dyes tend to be strongly UV-absorbing small molecules that emit relatively sharp fluorescence peaks with high quantum yields. They are relatively insensitive to the polarity and $\mathrm{pH}$ of their environment, and are reasonably stable in physiological conditions. Moreover, small modifications to their structures enable tuning of their fluorescence characteristics. Therefore, these dyes are widely used to label proteins and DNA, among others. Consequently, there is the potential that modifications to the BODIPY framework will lead to probes that can be used more effectively for imaging in living cells and whole organisms, but that this is still largely unrealized [1-5].

Having in mind earlier studies, by other groups, and also the research developed recently by our group [6,7], we report in this work the synthesis and evaluation of the optical properties of BODIPY derivatives having in mind their potential application as novel fluorescent probes for the detection of a wide range of analytes, such as neutral molecules and ions, as well for bio-imaging in living cells.

\section{Experimental Section}

\subsection{Materials and Methods}

NMR spectra were obtained on a Bruker Avance III 400 at an operating frequency of $400 \mathrm{MHz}$ for ${ }^{1} \mathrm{H}$ and $100.6 \mathrm{MHz}$ for ${ }^{13} \mathrm{C}$, using the solvent peak as internal reference. The solvents are indicated 
in parenthesis before the chemical shift's values [ $\delta$ relative to trimethylsilane (TMS)]. Peak assignments were made by comparison of chemical shifts, peak multiplicities, and $J$ values, and were supported by spin decoupling-double resonance and bidimensional heteronuclear techniques. All reagents were purchased from Sigma-Aldrich, Acros and Fluka, and used as received. Thin layer chromatography (TLC) analysis was carried out on $0.25 \mathrm{~mm}$ thick precoated silica plates (Merck Fertigplatten Kieselgel 60F254) and the spots were visualized under UV light. Chromatography on silica gel was carried out on Merck Kieselgel (230-400 mesh). UV-visible absorption spectra were obtained using a Shimadzu UV/2501PC spectrophotometer. Fluorescence spectra were collected using a FluoroMax-4 spectrofluorometer.

The relative fluorescence quantum yields were determined by using a $1 \times 10^{-5} \mathrm{M}$ solution of Rhodamine 6G in ethanol as standard $\left(\Phi_{F}=0.95\right)[8,9]$.

\subsection{Synthesis of BODIPY Derivatives}

General procedure: 2,4-dimethylpyrrole $(1.0 \mathrm{mmol})$ and 9-anthraldehyde $(1.0 \mathrm{mmol})$ (for 1$)$ or 4(diphenylamino)-benzaldehyde $(1.0 \mathrm{mmol}$ ) (for 2) were dissolved in dry dichloromethane (DCM) $(100 \mathrm{~mL})$ in the presence of a catalytical amount of trifluoroacetic acid (TFA). The reaction mixture was stirred at room temperature for 50 minutes. DDQ $(1.9 \mathrm{mmol})$ was dissolved in dry DCM (100 $\mathrm{mL})$, added to the reaction mixture, and stirred for 50 minutes. Triethylamine $(16 \mathrm{mmol})$ was added, followed by treatment with $\mathrm{BF}_{3} \mathrm{OEt}_{2}(26.8 \mathrm{mmol})$ with stirring for $30 \mathrm{~min}$. The mixture was evaporated under reduced pressure and the crude residue was subjected to a preliminary dry flash chromatography.

\subsubsection{BODIPY Derivative 1}

The crude residue was purified through a dry flash chromatography column using petroleum ether/ethyl acetate (4:1) as eluent. The BODIPY derivative 1 was obtained as a dark red solid (134 mg, $33 \%)$.

${ }^{1} \mathbf{H}$ RMN (400 MHz, $\left.\mathrm{CDCl}_{3}\right): \delta=0.67\left(\mathrm{~s}, 6 \mathrm{H}, \mathrm{CH}_{3}-1\right.$ and $\left.\mathrm{CH}_{3}-7\right), 2.65\left(\mathrm{~s}, 6 \mathrm{H}, \mathrm{CH}_{3}-3\right.$ and $\left.\mathrm{CH}_{3}-5\right), 5.91$ (s, $2 \mathrm{H}, \mathrm{H}-2$ and $\mathrm{H}-6), 7.43\left(\mathrm{dt}, J=1.2\right.$ and $8 \mathrm{~Hz}, 2 \mathrm{H}, \mathrm{H}-3^{\prime}$ and $\left.\mathrm{H}-8^{\prime}\right), 7.50\left(\mathrm{dt}, J=1.2\right.$ and $8.4 \mathrm{~Hz}, 2 \mathrm{H}, \mathrm{H}-4^{\prime}$ and $\left.\mathrm{H}-7^{\prime}\right), 7.94\left(\mathrm{dd}, J=0.8\right.$ and $8.8 \mathrm{~Hz}, 2 \mathrm{H}, \mathrm{H}-2^{\prime}$ and $\left.\mathrm{H}-9^{\prime}\right), 8.04$ (d largo, $J=8.4 \mathrm{~Hz}, 2 \mathrm{H}, \mathrm{H}-5^{\prime}$ and $\left.\mathrm{H}-6^{\prime}\right)$, 8.59 (s, 1H, H-1') ppm. $\left.{ }^{13} \mathbf{C ~ R M N ~ ( 1 0 0 . 6 ~ M H z , ~} \mathrm{CDCl}_{3}\right): \delta=13.29,14.67,121.15,125.07,125.72,126.93$, $128.25,128.32,129.66,131.28,132.35,138.94,142.87,155.74 \mathrm{ppm}$.

\subsubsection{BODIPY Derivative 2}

The crude residue was purified through a dry flash chromatography column using petroleum ether/ethyl acetate (4:1) as eluent. The BODIPY derivative 2 was obtained as an orange solid $(57.5 \mathrm{mg}$, $16 \%)$.

$\left.{ }^{1} \mathrm{H} \mathrm{RMN} \mathrm{(400} \mathrm{MHz}, \mathrm{CDCl}_{3}\right): \delta=1.60\left(\mathrm{~s}, 6 \mathrm{H}, \mathrm{CH}_{3}-1\right.$ and $\left.\mathrm{CH}_{3}-7\right), 2.57\left(\mathrm{~s}, 6 \mathrm{H}, \mathrm{CH}_{3}-3\right.$ and $\left.\mathrm{CH}_{3}-5\right), 6.02$ (s, 2H, H-2 and H-6), 7.06-7.19 (m, 9H, 9 × Ar-H), 7.22-7.27 (m, 5H, $5 \times$ Ar-H) ppm. ${ }^{13} \mathbf{C}$ RMN (100.6 MHz, $\left.\mathrm{CDCl}_{3}\right): \delta=14.56,121.16,123.30,123.46,124.72,128.881,129.45 \mathrm{ppm}$.

\section{Results and Discussion}

\subsection{Synthesis}

BODIPY derivatives 1 and 2 functionalized at the meso position were synthesized in two reactional steps. Initially, the condensation reaction of 2,4-dimethylpyrrole and the corresponding aldehyde, in the presence of TFA as catalyst, was carried out. The second reactional step consisted in the oxidation by DDQ followed by reaction with $\mathrm{BF}_{3} \mathrm{OEt}_{2}$ (Scheme 1). The crude residue was purified by a dry flash chromatography column. The products $\mathbf{1}$ and $\mathbf{2}$ were obtained as a dark red solid in $33 \%$ yield and an orange solid in $16 \%$ yield, respectively. The ${ }^{1} \mathrm{H}$ and ${ }^{13} \mathrm{C}$ NMR spectroscopy of compounds 1 and 2 confirmed the proposed structure. 


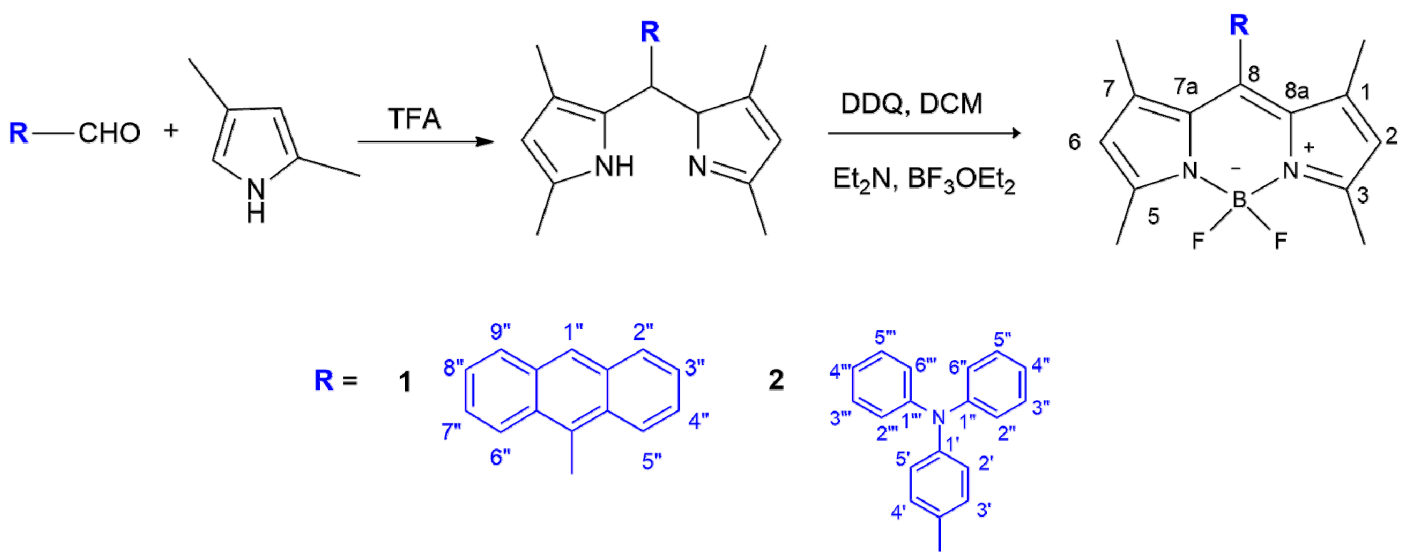

Scheme 1. Synthesis of BODIPY derivatives 1 and 2.

\subsection{Optical Properties Study}

The spectroscopic characterization of the two compounds was carried out in acetonitrile solutions. The BODIPY derivatives showed intense absorption bands ( $\log \varepsilon=3.96$ and 3.99, respectively) in the $497-502 \mathrm{~nm}$ region (Table 1 ).

The position of the absorption bands was dependent on the structure and electronic character of the substituent groups. When BODIPY was functionalized with the 9-anthracenyl group, a slight bathochromic shift occurred for the maximum absorption wavelength, when compared to the derivative with the triphenylamine group. In the case of compound 1, the 9-anthracenyl group exhibits greater planarity and extension of the $\pi$-conjugate system, leading to an absorption band at a longer wavelength.

Through the study of the emission of compounds $\mathbf{1}$ and $\mathbf{2}$, it was possible to observe bands with maximum emission wavelengths at $518 \mathrm{~nm}$ and $519 \mathrm{~nm}$. The relative fluorescence quantum yields, determined by using Rhodamine $6 \mathrm{G}$ in ethanol as standard, were found to be quite low and BODIPY derivative 2, functionalized with triphenylamine group, showed lower fluorescence quantum yield, comparatively to compound 1, probably due to the flexibility, which can lead to higher probability of occurrence of non-radiative relaxation. The Stokes' shifts of the two BODIPY derivatives were relatively short, as usual for this class of compounds [2].

Table 1. UV-visible absorption and emission data for 4,4-Difluoro-4-bora-3a,4a-diaza-s-indacene (BODIPY) derivatives $\mathbf{1}$ and 2.

\begin{tabular}{cccccc}
\hline \multirow{2}{*}{ Cpd } & \multicolumn{2}{c}{ UV-vis } & \multicolumn{3}{c}{ Fluorescence } \\
\cline { 2 - 6 } & $\lambda_{\max }(\mathbf{n m})$ & $\log \varepsilon$ & $\lambda_{\text {em }}(\mathbf{n m})$ & $\boldsymbol{\Phi}_{\mathrm{F}}$ & Stokes' Shift (nm) \\
\hline $\mathbf{1}$ & 502 & 3.99 & 518 & 0.011 & 16 \\
$\mathbf{2}$ & 497 & 3.96 & 519 & 0.005 & 22 \\
\hline
\end{tabular}

\section{Conclusions}

Two BODIPY derivatives were synthetized, bearing different substituents at the meso position, with a yield of $16 \%$ for BODIPY derivative $\mathbf{1}$ and 33\% for derivative 2 .

The influence of the electronic nature of the different substituent groups on the photophysical properties (absorption and emission) of BODIPY derivatives was evaluated in acetonitrile solutions. It was found that higher planarity and a greater conjugation of the 9-anthracenyl group inserted at the meso position of the BODIPY led to bathochromic deviation of the absorption band.

Acknowledgments: Thank are due to Fundação para a Ciência e Tecnologia (Portugal) and FEDER-COMPETE for financial support through Centro de Química (UID/ QUI/0686/2016). The NMR spectrometer Bruker Avance III 400 is part of the National NMR Network and was purchased within the framework of the National Program for Scientific Re-equipment, contract REDE/1517/RMN/2005 with funds from POCI 2010 (FEDER) and FCT. 
Conflicts of Interest: The authors declare no conflict of interest.

\section{References}

1. Freidus, L.G.; Pradeep, P.; Kumar, P.; Choonara, Y.E.; Pillay, V. Alternative fluorophores designed for advanced molecular imaging. Drug Discov. Today 2018, 23, 115-133, doi:10.1016/j.drudis.2017.09.008.

2. Loudet, A.; Burgess, K. BODIPY dyes and their derivatives: Syntheses and spectroscopic properties. Chem. Rev. 2007, 107, 4891-4932, doi:10.1021/cr078381n.

3. Li, L.; Nguyen, B.; Burgess, K. Functionalization of the 4,4-difluoro-4-bora-3a,4a-diaza-s-indacene (BODIPY) core. Bioorg. Med. Chem. Lett. 2008, 18, 3112-3116, doi:10.1016/j.bmcl.2007.10.103.

4. Zhang, Y.; Fang, H.-M.; Zhang, X.-T.; Wang, S.; Xing, G.-W. 8-(4-aminophenyl) BODIPYs as fluorescent pH probes: Facile synthesis, computational study and lysosome imaging. ChemistrySelect 2016, 1, 1-6, doi:10.1002/slct.201500016.

5. Deng, M.; Gong, D.; Han, S.-C.; Zhu, X.; Iqbal, A.; Liu, W.; Qin, W.; Guo, H. BODIPY based phenylthiourea derivatives as highly selective $\mathrm{MeHg}^{+}$and $\mathrm{Hg}^{2+}$ ions fluorescent chemodosimeter and its application to bioimaging. Sens. Actuators B Chem. 2017, 243, 195-202, doi:10.1016/j.snb.2016.11.139.

6. Presti, M.L.; Martínez-Máñez, R.; Ros-Lis, J.V.; Batista, R.M.F.; Costa, S.P.G.; Raposo, M.M.M.; Sancenón, F. A dual channel sulphur-containing macrocycle functionalised BODIPY probe for the detection of $\mathrm{Hg}$ (II) in mixed aqueous solution. New J. Chem. 2018, 42, 7863-7868, doi:10.1039/C7NJ04699E.

7. Hazem, E.O.; Sayed, S.E.; Ferreira, R.C.M.; Costa, S.P.G.; Raposo, M.M.M.; Martínez-Máñez, R.; Sancenón, F. 4(4,5-Diphenyl-1H-imidazole-2-yl)- $N, N$-dimethylaniline-Cu(II) complex, a highly selective probe for glutathione sensing in water-acetonitrile mixtures. Dyes Pigments 2018, 159, 45-48, doi:10.1016/j.dyepig.2018.05.069.

8. Montalti, M.; Credi, A.; Prodi, L.; Gandolfi, M.T. Handbook of Photochemistry, 3rd ed.; CRC Press: Boca Raton, FL, USA, 2006.

9. Demas, J.N.; Crosby, G.A. Measurement of photoluminescence quantum yields. Review. J. Phys. Chem. 1971, 75, 991-1024, doi:10.1021/j100678a001.

(C) 2019 by the authors. Licensee MDPI, Basel, Switzerland. This article is an open access article distributed under the terms and conditions of the Creative Commons Attribution (CC BY) license (http://creativecommons.org/licenses/by/4.0/). 